\title{
En torno a la Teoría de la Constitución y los nuevos contextos del constitucionalismo
}

\author{
Augusto Martín de la Vega \\ Profesor titular de Derecho constitucional \\ Universidad de Salamanca
}

Recibido: 04.12.09

Aceptado: 09.12.09

\begin{abstract}
Resumen: La literatura iuspublicista europea contemporánea está asistiendo a una revitalización de la Teoría de la Constitución. Existe en la doctrina una conciencia general sobre la oportunidad de repensar los presupuestos y fundamentos del Derecho constitucional. El autor defiende en este trabajo que se hace necesaria una Teoría de la Constitución que sea consciente de los cambios en el contexto filosófico, teórico y sociopolítico actual, y que evite que las reflexiones fundamentales del constitucionalismo se vacíen en teorías filosóficas de la justicia o de la comunicación y en teorías sociológicas del derecho, que puedan conducir a una desvalorización de la fuerza normativa y ordenadora del texto constitucional. Tres son los grandes rasgos que han de individualizar la reflexión sobre la Teoría de la Constitución: la existencia de un ambiente cultural que cambia paulatinamente, la evolución o transformación de las funciones del Estado y la necesidad de acometer una visión crítica de la Teoría de la Constitución asumiendo la variedad de métodos, objetivos y presupuestos conceptuales.
\end{abstract}

Palabras clave: Constitución, Teoría de la Constitución, constitucionalismo multinivel, legitimidad constitucional.

Abstract: The current European publicist literature is experiencing a revival of the Constitutional Theory. The large majority of the doctrine shares the view that this is a good opportunity to rethink the assumptions and fundamentals of Constitutional Law. The author defends in this paper that it is necessary for the Constitutional Theory to be aware of the changes arising at the philosophical, theoretical and sociopolitical level and therefore that avoids that the fundamental thoughts of the constitutionalism could create a context in which the normative and structural power of the Constitution would be undermined by philosophical theories, justice or legal sociology approaches that do not take into account the current social developments. There are three aspects that any analysis should take into account: the existence of a cultural context that changes constantly, the evolution of the State tasks (and powers) and the need to develop a critical approach of the Constitutional Theory that do take into account the numerous methodologies, objectives and foundations of the legal theory.

Key words: Constitution, Constitutional Theory, multilevel constitutionalism, constitutional legitimacy.

Sumario: 1. Los nuevos contextos del constitucionalismo. 1.1. El nuevo contexto cultural. 1.2. Crisis del Estado social y globalización. 
1.3. Algunos rasgos de la actual reflexión constitucional: giro teórico, perspectiva constituyente y dinamismo constitucional.-2. Problemas en torno al concepto de Constitución desde la perspectiva de la Teoría de la Constitución. 2.1. La Constitución como orden jurídico. 2.1.1. El ordenamiento como problema. 2.1.2. Los límites de la eficacia ordenadora de la Constitución. 2.2. La Constitución como orden fundamental de la Comunidad. 2.2.1. La Constitución como marco y como decisión fundamental. 2.2.2. La legitimidad democrática como fundamento de la constitución: pluralismo y constitucionalismo multinivel.

\section{Los nuevos contextos del constitucionalismo}

La revitalización de la Teoría de la Constitución, como instancia crítica de las soluciones aportadas por el derecho positivo como fuente de determinación de principios, reglas y modelos constituyentes y como filtro de racionalización de las precomprensiones constitucionales, puede considerarse uno de los rasgos más novedosos de la literatura iuspublicista europea contemporánea ${ }^{1}$. ¿Por qué actualmente parece necesario un enfoque más amplio del Derecho constitucional? Probablemente porque nos encontramos ante un cierto «malestar constitucional» ${ }^{2}$ que se plasma en la necesidad de buscar «una teoría general de la Constitución y de sus cambios que ofrezca instrumentos conceptuales y teóricos para afrontar el futuro» ${ }^{3}$. Como señala Zagrebelsky, existe una conciencia general sobre la oportunidad de repensar los presupuestos y fundamentos del Derecho constitucional ${ }^{4}$.

Se insiste cada vez más en la situación precaria del Derecho constitucional, que no parece poseer una metodología propia, ni siquiera una propia doctrina del método, y donde existen grandes dificultades para precisar su objeto, que presenta en todo caso considerables dependencias de lo político. Así las cosas, el Derecho constitucional se entiende más como límite que como contenido, más como medida que como norma, más como función que como estructura. Se advierte en suma la imposibilidad de abarcar la realidad constitucional sub specie legis o jurisprudencial, de comprender el sentido y relieve de una traducción en forma jurídica de los datos de hecho. Por otra parte, son tantas y tan diversas las esferas de la realidad afectadas por la nor-

${ }^{1} \mathrm{Vid}$. por todos, Gomes Canotilho, Direito Constitucional e Teoria da Constituição, Coimbra, 2003, pp. 1316, y Constituição dirigente e vinculação do Legislador, Coimbra, 2001, pp. 79 y ss.

${ }^{2}$ Gomes Canotilho, «Malestar de Constituçao e pesimismo posmoderno» en Luisiada, n. ${ }^{\circ}$, marzo 1991, pp. 57 y ss. Vid. también Lucas Verdú, La Constitución en la encrucijada (Palingenesia iuris politici), Madrid, 1994.

${ }^{3}$ Il futuro della Costituzione, AA. VV., Turín, 1999, op. cit., Introduzione, pp. XI.

${ }^{4}$ «Storia e costituzione», en Il futuro della costituzione, op. cit., pp. 37. 
ma constitucional, que impiden al derecho constitucional sostenerse tautológicamente sobre sí mismo sin pedir ayuda a otros sectores extrajurídicos ${ }^{5}$.

En este ámbito, una Teoría de la Constitución consciente de los cambios en el contexto filosófico, teórico y sociopolítico actual, puede evitar que las reflexiones fundamentales del constitucionalismo se vacíen en teorías filosóficas de la justicia o de la comunicación y en teorías sociológicas del derecho que conducen en definitiva a una desvalorización de la fuerza normativa y ordenadora del texto constitucional ${ }^{6}$.

Como pretensión constructiva es evidente que el esfuerzo sobrepasa con mucho los intentos singulares de los juristas, y actualmente se concreta, más allá de algún planteamiento global (Häberle) o más o menos crítico (Canotilho), en un nuevo enfoque que no deja de percibirse en parte de la literatura jurídica.

Es posible que nos hallemos ante una «moda» más, por la cual el jurista constitucional, para estar a la altura, debería dominar la concepción autopoiética del derecho o la teoría de la comunicación «habermasiana». Aun cuando haya algo de cierto en ello, y sin olvidar que las modas pueden representar un modo privilegiado de contrastar la constitución y sus normas con la realidad social, puede entenderse que nos encontramos ante una nueva forma de «experiencia constitucional».

En este sentido, y salvando las profundas diferencias históricas, es sugerente recordar la experiencia de Weimar. Es obvio que siempre ha existido una teoría de la Constitución como reflexión sobre los grandes temas del poder y la libertad política. El término mismo, Teoría de la Constitución, y su significado más preciso, como acercamiento crítico-dogmático a la idea de Constitución, nacen sin embargo en la Alemania del primer tercio de siglo, en relación crítica con la preeminencia del positivismo jurídico. El contexto de crisis del Estado constitucional burgués, y sus posteriores consecuencias históricas, dotarán de un significado especial a esta literatura. Sus sugerencias, no obstante, aún siguen nutriendo gran parte de las más fecundas reflexiones constitucionales.

Destacaremos aquí tan solo tres grandes rasgos que individualizan semejante reflexión, profundamente diversa y bien conocida por la doctrina española ${ }^{7}$. En primer lugar, esta se produce en un ambiente cultural que cambia

${ }^{5}$ Por todos, Cascajo Castro, «Notas para un breve ensayo sobre constitución e interpretación constitucional» en Estudios de Deusto, vol 51/1, 2003. Vid. también algunas de las respuestas a la encuesta sobre «Orientación y método del Derecho constitucional» en Teoría y Realidad constitucional, n. ${ }^{\circ}$ 21, 2008, o el artículo en el mismo número de Wolkmann V., «El derecho constitucional, entre pretensión normativa y realidad política, pp. 187 y ss.

${ }^{6}$ Gomes Canotilho, Direito Constitucional, op. cit., pp. 1337 y ss.

7 Vid. por todos, García Pelayo, Derecho Constitucional Comparado, Madrid, 1984, pp. 79 y ss., Lucas Verdú, La teoría constitucional de Rudolf Smend, Madrid, 1987, o Estévez Araujo, La crisis del Estado de Derecho liberal. Schmitt en Weimar, Barcelona, 1988. 
paulatinamente. La discusión en torno a las ciencias del espíritu como método aplicable al Derecho es el reflejo claro de una cierta crisis del positivismo cientifista en general.

En segundo término, se enmarca en un momento de transformación de las funciones del Estado, con su conversión paulatina hacia un activo agente social e intervensionista. En este sentido, si bien es clara la conciencia de los profundos enfrentamientos sociales e ideológicos que dominan la época, también lo es en parte la posibilidad de una estabilización a través del pacto constitucional.

En tercer lugar, dichas reflexiones constituyen, en el ámbito jurídico, una clara reacción contra el método positivista anterior, caracterizándose por realizar una reflexión sobre la esencia de la Constitución y sobre sus conceptos jurídicos límites (legitimación y poder constituyente, soberanía, constitución formal/material, entre otros muchos). Se produce así una enorme «policromía ${ }^{8}$ en cuanto a métodos, objetivos y presupuestos conceptuales, que adquiere un tono más crítico que fundante.

\subsection{El nuevo contexto cultural}

Volviendo a nuestra época, no resulta difícil afirmar que en este momento también se ha producido un cambio importante en el contexto cultural. En este sentido se habla de posmodernidad y de derecho constitucional posmoderno. La reflexión filosófica del siglo es obviamente mucho más amplia, y es posible detectar la continuación de una tradición analítica, otra marxistadialéctica, una tercera hermenéutica-fenomenológica y otra, más ecléctica, donde puede predominar el pragmatismo, el estructuralismo, el postestructuralismo o la posmodernidad en cuanto línea filosófica concreta ${ }^{9}$. Así y todo el concepto de posmodernidad puede quizás aún definir en términos generales y sincréticos el actual estado cultural ${ }^{10}$.

Lo que ha venido definiéndose como «la condición posmoderna» ${ }^{11}$ encuentra un elemento de identificación en su crítica global al concepto mis-

\footnotetext{
${ }^{8}$ Según la conocida expresión del discípulo de Smend, Hsü Dau Lin, acerca del concepto de Constitución en el Derecho político weimariano, «Formalistischer und antiformalisticher Verfassungsbegriff», en AöR, XXII, n. ${ }^{\circ} 1,1932$, pp. 30.

${ }^{9}$ Vid. Manuel Cruz, Filosofía contemporánea, Madrid, 2002, con una postura muy crítica sobre la importancia real del fenómeno y su permanencia en el tiempo. En el mismo sentido, U. Beck., La democracia y sus enemigos, Barcelona, 2000.

${ }^{10}$ Fehér, «La condición de la posmodernidad» en Fehér y Séller, Políticas de la postmodernidad, Barcelona, 1988, pp. 148 y ss., o Harvey, La condición de la posmodernidad, Buenos Aires, 2008. Una visión crítica tanto del proyecto ilustrado como de la situación actual, en la lúcida obra de Sloterdijk, Crítica de la razón cínica, Madrid, 2007, con un detallado análisis de lo que denomina «el síndrome de Weimar», op. cit. pp. 532 a 744.

${ }^{11}$ Lyotard, La condición posmoderna, Madrid, 1987. Curiosamente esta obra, precursora en parte del movimiento, tiene su origen en un informe del autor de 197, para el
} 
mo de modernidad como desarrollo racional y progresivo de la sociedad occidental basado en categorías centrales como generalidad y abstracción, planificación y heterodisciplina o funcionalidad ${ }^{12}$. La refutación de cualquier discurso entendido como metarrelato legitimante, constituye otra de las características esenciales del «espíritu de época». Se acentuará así no solo el carácter «ideológico» de todo «discurso» sino ante todo su naturaleza de sistemas aleatorios de sentido. El pesimismo en torno a cualquier ordenación finalista de la vida en común es una consecuencia inherente a esta actividad, desmitificadora de lo político y social ${ }^{13}$.

En el terreno del Derecho esta sensibilidad se desdobla en diversas perspectivas, que convergen en desvalorizar el Derecho del Estado en cuanto general, abstracto, heterónomo y planificador. En contraposición, se habla de un Derecho «de lo cotidiano», de un Derecho como «universo simbólico», remarcando las dimensiones no reflexivas ni funcionales de la norma jurídica, o de un Derecho flexible, que sustituya el centralismo y la abstracción de los sistemas jurídicos estatales por una arquitectura en red donde predomine la autoestructuración normativa ${ }^{14}$.

\subsection{Crisis del Estado del social y globalización}

La situación actual también se caracteriza por el aumento de las corrientes críticas ante el papel ordenador del Derecho en los modernos Estados de bienestar. Se cuestiona asimismo la permanencia del Estado como elemento central de la realidad política y económica.

Consejo Universitario del gobierno de Québec sobre la enseñanza de las humanidades y los nuevos cambios tecnológicos.

${ }^{12}$ Vid. Hal Foster, «Introducción al posmodernismo», en La posmodernidad, Habermas, Braudillard, Said, Jameson y otros, Barcelona, 1985. Una crítica a esta idea de cierre de la modernidad, en Habermas, «La modernidad, un proyecto incompleto», en La posmodernidad, Barcelona, 1983.

${ }^{13}$ Vid. Baum, La posmodernidad y sus descontentos, Madrid, 2001, Fischer, Retzer y Scheizer (comp.), El final de los grandes proyectos, Barcelona, 1997 o Gil Villa, Individualismo y cultura moral, Madrid, 2001.

${ }^{14}$ Vid. Hespana, Cultura jurídica europea, Madrid, 2002, pp. 248 y ss. Sobre el derecho reflexivo, Teubner, «After Legal Instrumentalism? Strategic Models of Posregulator Law» en International Journal of Sociology of Law, 1984. En España, vid. por ejemplo, un primer acercamiento en Martinez-Carrasco Pignatelli, Postmodernidad y Derecho Público, Madrid, 2002, o Fariñas Dulce, Los Derechos Humanos: desde la perspectiva sociológica a la «actitud postmoderna», Madrid, 2006. Uno de los escasos autores españoles que ha abordado la relación entre posmodernidad y Derecho constitucional es Eloy García en su «Estudio preliminar» a la obra de Pocock, El momento maquiavélico. El pensamiento político florentino y la tradición republicana atlántica, Madrid, 2008. 
Ferrajoli ${ }^{15}$ sostiene que en los países de democracia más avanzada estamos asistiendo a una crisis profunda y creciente del Derecho, que se manifiesta en diversas formas y en múltiples planos. Dentro de ellos distinguirá tres aspectos. Una crisis de la legalidad, en cuanto a las reglas vinculantes para los titulares de los poderes públicos, y que se expresa en la ausencia o insuficiencia de los controles y, por tanto, en una variada y llamativa fenomenología de la ilegalidad del poder. En segundo lugar, la inadecuación estructural de las formas del Estado de derecho a las funciones del Estado del bienestar. Desde una perspectiva más conservadora, Dieter Grimm ${ }^{16}$ considera que las insuficiencias regulativas detectadas en la Constitución y en el ordenamiento estatal se deben a una contradicción entre el paradigma clásico del Estado de derecho, que se basaría en un conjunto de límites y prohibiciones jurídicas por parte del poder público, y el del Estado social, que demanda de estos mismos poderes la satisfacción de derechos sociales mediante prestaciones positivas. No solo se incrementarán así las tareas de regulación y control que incumben al Estado, sino que cambiará la propia naturaleza de sus funciones. Con ello se modifica el diseño del ordenamiento, que adquiere un carácter prospectivo, la finalidad de la actividad estatal, que se fundamenta en el logro de la seguridad y en la prevención, y en último término cambian también los instrumentos de acción. El mandato normativo se sustituye por una negociación, donde los grupos sociales y los partidos políticos diluyen las fronteras materiales y subjetivas entre estado y sociedad. La legalidad pierde por tanto su carácter de generalidad y abstracción, y adquiere una nota de fragmentación y corporativismo. En el nivel constitucional, Grimm se plantea si nos encontramos ante un déficit de adecuación o ante una inadecuación del propio instrumento constitucional ${ }^{17}$.

Desde distinta perspectiva, Habermas se preguntará si esta falta de eficacia vinculante del Derecho y esta «atrofia constitucional» no implica más bien un problema de efectividad del aparato estatal y de necesaria limitación de los instrumentos jurídicos, que no afecta al nivel constitucional, al ámbito de la legitimidad. En todo caso el problema apunta a la necesidad de vigorizar democráticamente el Derecho como mediación entre facticidad y validez ${ }^{18}$.

En tercer lugar, nos encontraríamos ante una crisis del Estado nacional, que se manifiesta en el cambio de los lugares de la soberanía, en la alteración del sistema de fuentes y, por tanto, en un debilitamiento del constitucio-

\footnotetext{
${ }^{15}$ L. Ferrajoli, Derechos y Garantías. La ley del más débil, Madrid, 2001, pp. 15 y ss.

16 «Il futuro della Costituzione», op. cit.

${ }^{17}$ Vid. también, el mismo cuestionamiento en O. Beaud, «Constitución» y «Constitucionalismo» en Raynaud y Rials (eds.), Diccionario Akal de Filosofía Política, Madrid, 2002.

${ }^{18}$ Vid. Habermas, Facticidad y validez. Sobre el Estado democrático de derecho en términos de teoría del discurso, Madrid, 1998, pp. 515 y ss.
} 
nalismo. Los procesos de interconexión mundial, y específicamente el de integración europeo, serían así los nuevos ejes espaciales del problema del poder político.

No se pretende aquí una descripción ni siquiera somera del complejo y debatido fenómeno de la globalización o internacionalización, un problema que ocupa a múltiples ramas científicas desde la década de los ochenta. Se subrayarán, no obstante, algunos de los rasgos que afectan sin duda a la Constitución como norma básica del Estado nacional. La globalización implica un desplazamiento del ámbito espacial de las organizaciones humanas hacia pautas de actividad e interacción interregionales y transcontinentales. Alude, pues, al menos, a dos fenómenos distintos, al que consiste en el alcance mundial de múltiples cadenas de actividad política y social, y al que implica una intensificación de los niveles de interconexión entre Estados y sociedades ${ }^{19}$. La globalización abarca por tanto una serie compleja de fenómenos a menudo contradictorios entre sí. No solo existiría un efecto expansivo, sino también una presión desde ámbitos territoriales inferiores al Estado. En la conocida expresión de Bell, «la nación se hace no solo demasiado pequeña para solucionar los grandes problemas, sino también demasiado grande para arreglar los pequeños».

David Held clasifica y analiza los cambios producidos en cuatro grandes campos, el de la economía mundial, el de la toma de decisiones de políticas internacionales, el del Derecho internacional regulativo, y por último el ámbito cultural y su entorno, ante todo en su faceta medioambiental y mediática $^{20}$. Este mismo autor realiza una precisión importante: desde la perspectiva jurídico-política cabe distinguir entre la soberanía del Estado, -como derecho a gobernar un territorio delimitado- y su autonomía, en cuanto que poder real del Estado nacional para articular metas políticas de manera independiente. De un análisis del fenómeno globalizador en los cuatro anteriores ámbitos mencionados, podría deducirse con claridad que el Estado encuentra ya muy limitada su autonomía y empieza a verse afectado cada vez en mayor medida por su soberanía. Un soberanía que, lejos de los términos clásicos, tiende a ser concebida actualmente como dividida entre un número de organismos nacionales, regionales o internacionales, y limitada por su propia pluralidad ${ }^{21}$.

Desde el punto de vista del ordenamiento nacional, esta globalización afecta, según Habermas, tanto a la seguridad y efectividad de la Administración del Estado, como a la identidad colectiva, como a la propia legitimación

${ }^{19}$ Giddens, Un mundo desbocado. Los efectos de la globalización en nuestras vidas, Madrid, 2002, pp. 25 y ss.

${ }^{20}$ Held, Modelos de Democracia, Madrid, 2001, pp. 381 y ss.

${ }^{21}$ Ibídem. pp. 393, vid. también, por todos, Castells, La sociedad red (La era de la información, vol. I), Madrid, 1997. 
democrática del Estado-nacional, produciendo así verdaderos «agujeros de legitimidad $»^{22}$. Estaríamos hoy, como ciudadanos integrados en un «demos», sujetos a un imparable proceso de «heteronomización $»^{23}$.

Más allá de la específica problemática europea, parece cierto que, como se ha señalado, la mundialización conlleva una cierta crisis del principio democrático, replanteando los viejos problemas del tiempo y el espacio en el Derecho constitucional ${ }^{24}$. El propio Hesse ha formulado, en términos sencillos pero radicales, el problema central: «la concepción tradicional del Estado es tan difícilmente mantenible como una idea de Constitución orientada al modelo nacional a la vieja usanza» ${ }^{25}$. Y es por ello por lo que en la presentación de su manual colectivo de Derecho constitucional subrayará la necesidad de abordar también jurídicamente estos cambios, al ser este «el objeto de una moderna Teoría de la Constitución, que debe contribuir a consolidar, desplegar y progresar el nuevo orden estatal y a incardinarlo en la Unión Europea ${ }^{26} \gg$.

\subsection{Algunos rasgos de la actual reflexión constitucional: "giro teórico», perspectiva constituyente y dinamismo constitucional}

Existe en el Derecho constitucional más reciente una mayor variedad de enfoques e intereses que hace tan solo dos décadas. La acentuación de esta nueva policromía no puede implicar, evidentemente, un paralelismo radical con situaciones anteriores. La Teoría de la Constitución alemana del primer tercio del siglo buscaba, con la notoria excepción de SchMiтt, la coexisten-

\footnotetext{
${ }^{22}$ Habermas, «La constelación posnacional y el futuro de la democracia», en La constelación posnacional, Barcelona, 2000, pp. 92 y ss. Vid. también del mismo autor «El Estado nacional europeo. Sobre el pasado y el futuro de la soberanía y de la ciudadanía», en $L a$ inclusión del otro. Estudios de Teoría Política, Barcelona, 1999. Gadamer, por su parte, señala su convencimiento «de que no solo el marco de pensamiento nacional-estatal, sino también el europeo, se revelarán como sobrepasados», en Carsten Dutt (ed.), Conversación con Hans-Georg Gadamer, Madrid, 1998, pp. 99.

${ }^{23}$ Vallespín, El futuro de la política, Madrid, 2000, pp. 160 y ss.

${ }^{24}$ Pedro de Vega, «Mundialización y derecho constitucional: la crisis del principio democrático en el constitucionalismo actual», Revista de Estudios Políticos, 1998, pp. 13 y ss. o Teubner, «Globalización y constitucionalismo social: alternativas a la Teoría Constitucional centrada en el Estado» en Anuario de la Facultad de Derecho de la UAM, n. ${ }^{\circ}$ 9, 2005. Vid. también, desde perspectivas más generales, Cassese, La globalización jurídica, Madrid, 2006, o Twining, Derecho y globalización, Bogotá, 2003. En la doctrina española, Mir puignalat O, Globalización, Estado y Derecho. Las transformaciones recientes del derecho Administrativo, Madrid, 2004.

${ }^{25}$ Hesse, «Constitución y Derecho Constitucional», en Manual de Derecho Constitucional, op. cit., pp. 15, o como subraya el título de la obra de Grasso, El problema del constitucionalismo después del Estado moderno, Madrid, 2005.

${ }^{26}$ Hesse, «Presentación» al Manual de Derecho Constitucional, Madrid, 1996, pp. XIX.
} 
cia de una sociedad profundamente dividida a través del papel integrador del pacto constitucional. Los frutos de ese intento corresponden en mayor medida al constitucionalismo de posguerra. Como señalara ZAGREBELSKY ${ }^{27}$, los textos de esta época configuran un gran acuerdo político-social que se plasma en la articulación del Estado del bienestar europeo y que incorpora la idea de una sociedad abierta y plural, pero sin enfrentamientos antagónicos. Es esta misma posibilidad la que va a permitir un desarrollo de la «dogmática constitucional», que alcanza en su vertiente analítica y garantista un elevado grado de elaboración, y que se consagra con la actividad efectiva de los Tribunales Constitucionales ${ }^{28}$. En la situación actual, pues, no se parte de la necesidad de consolidar un estado democrático-constitucional, sino del triunfo de este sobre cualquier cosmovisión antagónica ${ }^{29}$. En España, los treinta años de Constitución y la evolución de nuestro Derecho constitucional arrojan un resultado sin duda satisfactorio ${ }^{30}$.

Es este el contexto en el que hay que encuadrar correctamente la crítica a lo que ha venido definiéndose como «positivismo jurisprudencial» ${ }^{31}$. Frente al rechazo «weimariano» al positivismo formalista y estatalista de finales de siglo, y cuyas implicaciones teórico-constitucionales han sido subrayadas en múltiples ocasiones ${ }^{32}$, este nuevo planteamiento apunta, en tonos más o menos críticos, a un seguidismo excesivo de los criterios marcados por la jurisdicción constitucional, y en último caso, a una excesiva reducción de la «problemática constitucional» a la dogmática de la interpretación del texto fundamental.

Situado en sus justos términos, el argumento asumible de este discurso coincidiría con su denuncia de una jurisprudencia utilizada como Deus ex machina capaz de solventar todos los problemas de la interpretación constitucional mediante el recurso al empleo de afirmaciones sustentadas en el texto de las sentencias constitucionales que guarden alguna relación con el tema a resolver o el mandato a interpretar. Dicho en forma más simplista, planearía especialmente sobre nuestra doctrina, como ha señalado

\footnotetext{
${ }^{27}$ Zagrebelsky, Giustizia Costituzionale, Bolonia, 1993.

${ }^{28}$ Vid. Acosta, Formación de la Constitución y jurisdicción constitucional. Fundamentos de la democracia constitucional, Madrid, 1998.

${ }^{29}$ Sartori, La democracia después del comunismo, Madrid, 1993, pp. 16 y ss.

${ }^{30}$ Por todos, Herrero de Miñón, «Entre la alegría y la confianza», en 20 años después. La Constitución cara al siglo XXI, Madrid, 1998, pp. 7 y ss, o López Aguilar, Lo constitucional en el derecho: sobre la idea e ideas de Constitución y orden jurídico, Madrid, 1998.

${ }^{31}$ Lucas Verdú, La Constitución en la encrucijada, op. cit., pp. 65 y ss. o Pedro de Vega, «El tránsito del positivismo jurídico al positivismo jurisprudencial en la doctrina española», Teoría y Realidad constitucional, 1998, pp. 65 y ss., Madrid, 1998.

${ }^{32}$ Vid. por todos, lúcidamente, el propio C. Schmitt, en Sobre los tres modos de pensar la ciencia jurídica, Madrid, 1996, pp. 32 y ss, o en «Hugo Preuss e la dottrina tedesca dello Stato», en Democracia e liberalismo, Milán, 2001, pp. 102 y ss.
} 
López Guerra, el peligro de un cierto «talmudismo constitucional-jurisprudencial» ${ }^{33}$.

Desde otro punto de vista, y dentro de la lógica diversidad nacional, sí pueden destacarse también algunos rasgos, característicos de la reflexión constitucional general de los últimos años. No existen dudas sobre la importancia y solidez alcanzada por una «metódica constitucional» que proporciona instrumentos rigurosos, en el plano de los conflictos de derechos, de la interpretación, de la ponderación de bienes o de la estructura de la norma, para concretar el Derecho constitucional en la práctica. Pero frente a esta perspectiva analítica, surge una tendencia difusa a recuperar lo que Alexy ya denominó perspectiva normativa, y que junto a la dimensión empírica, contribuye a dotar a la ciencia del derecho como disciplina práctica de un principio de unidad ${ }^{34}$. Así, hoy en día cobran mayor realce las teorías materiales o más propiamente generales, sobre los derechos fundamentales, que el propio Alexy considera de escasa utilidad a la hora de la aplicación jurisprudencial del Derecho ${ }^{35}$. Como señala Gomes Canotilho ${ }^{36}$, desde mediados de los setenta, los intentos por elaborar una teoría de los derechos fundamentales, y cuyas variantes sintetizará ya clásicamente Böckenförde ${ }^{37}$, presuponían que alguna de ellas podía ofrecer una comprensión lógica, global y coherente de todos los preceptos constitucionales. Lo cierto es que su localización en una teoría de la Constitución no dejaba de ser incierta y pronto fueron acercándose a la filosofía, a la vez que se iniciaba el «giro dogmático» que tan bien representarían autores como Alexy. Hoy en día parece, en cambio, sentirse la necesidad de una teoría basada en la Constitución positiva y que tenga en cuenta la realidad plural de los derechos y su evidente multifuncionalidad $^{38}$.

Este mismo «giro teórico» puede percibirse en la mayor atención que la literatura jurídico-constitucional viene prestando a las construcciones generales sobre el sentido y los límites de la jurisdicción constitucional, donde elaboraciones como la de Ely, Dorwkin y Ackerman o Waldron ${ }^{39}$ implican en

${ }^{33}$ López Guerra, Revista Teoría y realidad constitucional, n. ${ }^{\circ}$ 1, 1998, pp. 43.

${ }^{34}$ Vid. Alexy, Teoría de los Derechos Fundamentales, Madrid, 2001, pp. 32 y ss.

${ }^{35}$ Ibídem.

${ }^{36}$ Direito Constitucional e Teoría da Costituçao, op. cit., pp. 1377 y ss.

${ }^{37}$ Böckenförde, «Teoría e interpretación de los derechos fundamentales» en Escritos sobre Derechos Fundamentales, Baden-Baden, 1993, pp. 44 y ss. Vid. también, Fioravanti, Los derechos fundamentales. Apuntes de historia de las constituciones, Madrid, 2000, pp. 25 y ss.

${ }^{38}$ Canotilho, Direito Constitucional e Teoría de la Constituçao, op. cit., pp. 1384 y ss.

${ }^{39}$ Dworkin, Los derechos en serio, Barcelona, 1984. Ely, Democracia y desconfianza. Una teoría del control de constitucionalidad, Santafé de Bogotá, 1997, Ackerman, La política del diálogo liberal, Barcelona, 1999, o Waldron, Derechos y desacuerdos, Madrid, 2005. En España, Ferreres comella, Justicia constitucional y democracia, 2. ${ }^{a}$ ed., Madrid, 2007. 
sí mismas verdaderas teorías sobre la Constitución. En igual sentido, parece orientarse el entendimiento de los principios de estructuración territorial del Estado como principios constitucionales clave ${ }^{40}$, y su nueva dimensión estructural a la hora de reflexionar sobre la Constitución europea ${ }^{41}$.

Junto a este «giro teórico», es importante la revitalización de una «perspectiva constituyente» en el Derecho constitucional. Y ello en varios sentidos. En primer lugar, la caída de los antiguos regímenes del Este supuso la aparición de una ola «constituyente» desconocida en el continente en medio siglo, y que reabre tanto la funcionalidad del Derecho comparado como la ingeniería constitucional, en su sentido más amplio ${ }^{42}$. En segundo término, adquiere vigor una consideración de la Constitución como «norma cuya cualidad diferencial consiste en construir a la comunidad política». En España ha sido sin duda Garrorena quien más claramente ha remarcado que con este nuevo enfoque se consigue tanto recuperar la dimensión de «totalidad» de la norma como tener en cuenta a los elementos no jurídicos presentes en el momento constituyente. Se evitará además la peligrosa tendencia a extremar el carácter abierto de los mandatos constitucionales ${ }^{43}$.

Esta perspectiva implica también, en tercer lugar, una revitalización de la reflexión constitucional sobre el propio poder constituyente ${ }^{44}$, concebido cada vez en mayor medida como autovinculación de la soberanía popular a través de un compromiso relativo a ciertos principios históricamente enmarcados $^{45}$. Con ello reaparece como problema central en términos jurídicos el principio democrático y sus implicaciones ${ }^{46} \mathrm{y}$, a su vez, adquieren mayor significado los nuevos estudios sobre el sentido histórico del constituciona-

${ }^{40}$ Häberle, El Estado constitucional, México, 2001, pp. 261 y ss.

${ }^{41}$ Vid. por todos, La Pergola, Los nuevos senderos del federalismo, Madrid, 1994.

${ }^{42}$ Vid. Elster, «Vinculi costituzionali e paradosso della democracia» en Il futuro de la Costituzione, op. cit., pp. 167 y ss.

${ }^{43}$ Garrorena, «Cuatro tesis y un corolario sobre el derecho constitucional», Revista Española de Derecho Constitucional, n. ${ }^{\circ}$ 51, 1997, pp. 45 y ss.

${ }^{44}$ Vid., por todos, Böckenförde, «El poder constituyente del pueblo. Un concepto límite del Derecho Constitucional» en Estudios sobre el Estado de Derecho y la democracia, Madrid 2000, pp. 159, Ackerman, La política en el diálogo liberal, op. cit., Holmes, «Vincoli costituzionali e paradosso della democracia» en Il futuro della Costituzione, op. cit.

${ }^{45}$ Sobre el concepto de autovinculación como explicación de la génesis constitucional vid. Elster, Ulises y las sirenas. Estudios sobre racionalidad e irracionalidad, México, 1980, pp. 152 y ss. Un importante replanteamiento de la veracidad de esta tesis, en el libro del mismo autor: Ulises desatado. Estudios sobre racionalidad, precompromiso y restricciones, Barcelona, 2002, pp. 111 y ss. La importancia del condicionamiento histórico-cultural en la elaboración de los nuevos textos fundamentales es acertadamente remarcada por Häberle, Pluralismo y Constitución. Estudios de Teoría Constitucional de la sociedad abierta, Madrid, 2002, pp. 50 y ss., y El Estado constitucional, op. cit., pp. 135 y ss.

${ }^{46} \mathrm{Vid}$., por todos, Böckenförde «La democracia como principio constitucional», en Estudios sobre el Estado de Derecho y la democracia, op. cit., pp. 47. o en España, Aragón, Constitución y democracia, Madrid, 1989. 
lismo ${ }^{47}$. En este contexto cobrará también importancia la reivindicación de la trascendencia de la «cultura constitucional» como «humus» necesario de toda ley fundamental ${ }^{48}$.

Por último, esta acentuación del elemento cultural y social lleva en ocasiones a concebir la Constitución como punto de llegada más que como punto de partida, subrayando el aspecto dinámico de la norma. No se trata, sin embargo, de una comprensión meramente formal-procesal de esta, como simple instrument of government (Hennis). Se acerca más a los postulados de Smend, cuando afirma la naturaleza de la Constitución «como realidad integradora permanente y continua», o de la «Constitución en el tiempo» de Bäumlin. Así, y adaptando también el concepto dinámico implícito en la construcción de autores como Hesse y su concepción de la «voluntad de Constitución», adquiere relevancia la idea de U. Preuss ${ }^{49}$ según la cual «una sociedad está articulada y constitucionalizada cuando se confronta consigo misma en las adecuadas formas institucionales y procesos normativamente dirigidos de adaptación, de resistencia y de autocorreción». Esta concepción encontrará acogida en un autor como Habermas, quien desde su entendimiento procedimental del Derecho y de la Constitución considera a la ley fundamental como «un proceso falible de aprendizaje por el que una sociedad supera progresivamente su incapacidad para autotematizarse normativamente ${ }^{50}$. El mismo planteamiento subyace también lógicamente en Häberle, quien, sin renunciar a la positividad de la norma, acentúa el aspecto dinámico y de aprendizaje, a la vez que el entendimiento de la Constitución desde un «pensamiento de posibilidades ${ }^{51}$. Lejos de los presupuestos últi-

${ }^{47}$ Autores como Fioravanti, Constitución, de la antigüedad a nuestros días, Madrid, 2001, o Los Derechos Fundamentales, Madrid, 2000, o Matteuci, Organización del poder y libertad. Historia del constitucionalismo moderno, Madrid, 1998, en Italia recuperarán la tradición de un Macllwain o un Kriele. Vid. también las reflexiones de Zagrebelsky, Historia y Constitución, Madrid, 2005.

${ }^{48}$ Así, Häberle ha realizado un intento teórico general de comprender la teoría de la Constitución como ciencia cultural, y específicamente como ciencia jurídica de los textos y la cultura. Acentuando la perspectiva integracionista, se concibe a la Constitución no sólo como texto jurídico, sino también como contexto cultural. Lo jurídico así es tan solo un aspecto de «la Constitución como cultura». El análisis textual comparativo permite no obstante que la Teoría de la Constitución y la ciencia del Derecho devengan por esta vía ciencia de la realidad. Vid. un planteamiento especialmente clarificador en Häberle, Libertad, igualdad, fraternidad, 1789, como historia, actualidad y futuro del Estado constitucional, Madrid, 1998, y con mayor densidad teórica, Pluralismo y Constitución, op. cit., y Teoría de la Constitución como ciencia de la cultura, Madrid, 2000. Una exposición global del pensamiento «häberliano» en El Estado Constitucional, México, 2001.

${ }^{49}$ Preuss, Revolution, Fortschrift und Verfassung, Berlín, 1990, pp. 73.

${ }^{50}$ Habermas, Facticidad y validez, op. cit., pp. 531.

${ }^{51}$ Häberle, El Estado constitucional, op. cit., pp. 3 y ss. 49 y ss. o 119 y ss. 
mos de Häberle, un autor como Canotilho adopta también la definición de PREUSS, y entiende que la complejidad y contingencia de la sociedad contemporánea exige así «una reescritura permanente de las reglas constitucionales con base en experiencias y aprendizajes, y no el recurso a integracionismos ético-sociales, a unitarismos políticos o a homogeneizaciones de los ciudadanos» ${ }^{52}$.

Si la Constitución del pluralismo se concibe como un punto de llegada ${ }^{53}$ adquieren importancia las «políticas constitucionales», entendidas como la configuración consciente y el desarrollo progresivo de una Constitución. En este sentido, señalará Häberle que, siendo estas una búsqueda de un buen ordenamiento constitucional, no pueden rechazarse por verse como demasiado próximas a la política, ya que hoy son especialmente necesarias en la nueva «era de la Constitución» tras $1989^{54}$. Si la Constitución de una sociedad pluralista es en realidad un «compromiso de posibilidades», resulta lógico que, para Zagrebelsky, la política constitucional consista en la realización del texto fundamental en uno de los cambiantes equilibrios en los que puede hacerse efectivo. O más gráficamente, «el Derecho constitucional es un conjunto de materiales de construcción, pero el edificio concreto no es obra de la Constitución en cuanto tal, sino de una política constitucional que versa sobre las posibles combinaciones de esos materiales». Parece evidente, sin embargo, que esta idea de una «Constitución en construcción», llevada a sus últimas consecuencias, puede terminar afectando a su propia fuerza normativa.

La historia del «concepto teórico de Constitución se ha movido siempre en el Estado constitucional democrático en torno a unos topoi clásicos como «historicidad», «proceso», «consenso-compromiso», «unidad-ordenación», y «apertura». La acentuación excesiva de cualquiera de ellos implica una pérdida del valor explicativo de las funciones de la norma en el sistema no del todo justificable. Sin caer en sincretismos reductores, pero de manera realista, Häberle subraya que un análisis comparativo de los textos constitucionales más actuales permite encontrar suficientes razones para aceptar una noción «mixta» de Constitución que dejara atrás las tradicionales posiciones enfrentadas ${ }^{55}$.

${ }^{52}$ Canotilho, Direito Constitucional e Teoria da Constituição, op. cit., pp. 224 y ss.

${ }^{53}$ Zagrebelsky, «Storia e costituzione», op. cit., pp. 74-75.

${ }^{54}$ Häberle, El Estado constitucional, op. cit., pp. 303.

${ }^{55}$ Ibídem, pp. 115. 


\section{Algunos problemas en torno al concepto de Constitución desde la perspectiva de la Teoría de la Constitución}

El nuevo contexto cultural, sociopolítico y teórico en que parece moverse el pensamiento constitucional en la actualidad no deja de plantear interrogantes hacia las precomprensiones de la norma fundamental más o menos compartidas desde la dogmática del Derecho constitucional. Es aquí donde la perspectiva de una Teoría general de la Constitución permite enmarcar una serie de problemas importantes para una completa inteligencia del significado de la Constitución en las sociedades democráticas contemporáneas. Se apuntarán aquí tan solo algunas de ellas, partiendo de la conocida definición de Hesse de la Constitución como orden jurídico fundamental de la Comunidad $^{56}$.

\subsection{La Constitución como orden jurídico}

\subsubsection{EL ORDENAMIENTO COMO PROBLEMA}

La noción de Constitución como orden jurídico alude, sin duda, a la necesaria función de ordenación normativa que, como ya señalamos, cumple toda ley fundamental. Pueden subrayarse sin embargo dos aspectos fundamentales de esta idea. En primer lugar, y como indica la mayoría de la doctrina, actualmente no cabe concebir el ordenamiento jurídico en los términos en que lo hacía el positivismo estatalista de comienzos de siglo. Como ha remarcado Zagrebelsky, por una parte, la premisa de la total estatalidad del Derecho es puesta en duda por las sociedades pluralistas actuales; y, por otra, la propia unidad del ordenamiento ya no es un dato sino un difícil proble$\mathrm{ma}^{57}$. Los ordenamientos jurídicos reales son hoy órdenes jurídicos pluralistas, incompletos e integradores pero no «integracionistas». En definitiva, son sistemas complejos, compuestos por normas, instituciones y derechos, cuya integración es un resultado que no siempre es conseguir de forma rigurosa ${ }^{58}$. Existe actualmente, además, una pluralidad de ordenamientos que se reclaman superiores y que son parcialmente concurrentes, de los que el Derecho comunitario y sus relaciones con el constitucional suponen el mejor ejemplo. A su vez, la propia concepción de la Constitución como un sistema abierto de reglas y principios, y la sustitución del principio de legalidad por el de constitucionalidad como criterio rector de la validez de la norma, implican profundos cambios ya evidentes en la concepción del Derecho, pero, ante todo, en la metodología jurídica apropiada a la nueva realidad. Como señala

\footnotetext{
${ }^{56}$ Hesse, Escritos de Derecho Constitucional, Madrid, 1992, pp. 3.

${ }^{57}$ Zagrebelsky, Il Diritto mitte, Turín, 1992, op. cit., pp. 39.

${ }^{58}$ Canotilho, Direito Costitucional, op. cit., pp. 1127.
} 
Canotilho, quien cree aún en una mecánica transposición de los métodos de un «epigonismo positivista» en la integración del Derecho (la solución se encuentra en el texto, y la interpretación/aplicación de las normas es aplicación de una regla general y condicionada suficientemente definida en los «códigos»), «no sabe nada de derecho constitucional» ${ }^{59}$.

Conviene, pues, partir de la base de que no es posible, trasladando antiguas concepciones, entender la unidad jurídica que pretende la Constitución como mecánica unificación de arriba abajo, por medio de una fuerza jerárquica superior que se desarrolla unilateral y deductivamente a partir de la Constitución ${ }^{60}$. La idea de la pirámide geométrica, debe pues matizarse y los propios resultados de una jurisdicción constitucional establecida para garantizar la supremacía jurídica de la norma fundamental cada vez lo confirma más. La dimensión valorativa y de ponderación del juicio de constitucionalidad se une a un entendimiento flexible del binomio inconstitucionalidad/ nulidad de la norma que altera profundamente el esquema kelseniano ${ }^{61}$. La unidad jurídica conseguida por la Constitución es pues, en todo caso, a posteriori y no a priori. Es contingente, en cierto modo parcial, y basada ante todo en una concepción de esta como norma fundamental y superior del ordenamiento, estructurada según reglas y principios $^{62}$.

\footnotetext{
${ }^{59}$ Canotilho, Direito Costitucional, op. cit., pp. 1103.

${ }^{60}$ Luhmann, «La Costituzione como acqusizione evolutiva», Il futuro della Costituzione, op. cit., pp. 111.

${ }^{61}$ Vid. por todos, Aja, Las tensiones entre el Tribunal Constitucional y el legislador en la Europa actual, Madrid, 1998.

${ }^{62}$ Es a esta realidad, que surge del desarrollo del modelo constitucional de la posguerra, a la que intenta dar respuesta teórica el llamado, quizás impropiamente, neoconstitucionalismo, y que encuentra en autores como Dworkin, Alexy, Ferrajoli, El último zagrebelky o Nino, sus exponentes más cualificados. Aun cuando puede hablarse de neoconstitucionalismo en múltiples sentidos, se trata en general de una denominación que engloba diversas posiciones teóricas y metodológicas, pero que coinciden en subrayar como elementos claves para la comprensión del Derecho occidental contemporáneo, su fuerte constitucionalización y su materialización en torno a valores y principios. A excepción de Ferrajoli, a todos ellos les une una común oposición al positivismo jurídico, sin caer por otra parte en el iusnaturalismo tradicional. En todo caso, y en paralelo a la conocida reflexión de Bobbio sobre el positivismo, puede hablarse como señala Comanducci del neoconstitucionalismo como método jurídico, como ideología y como teoría del Derecho. Es en esta última faceta donde parece cobrar mayor pujanza dentro de la filosofía del Derecho, y donde la tendencia a subrayar los vínculos entre derecho y moral suscita mayores recelos y respuestas teóricas como las del positivismo incluyente. Por otra parte, desde la óptica adoptada en este trabajo, el neoconstitucionalismo no deja de recordar a la Minerva filosófica en cuanto supone una reflexión, por otra parte muy fructífera, reflexión, en torno a un tipo de constitución y de constitucionalización del ordenamiento que, alcanzando su apogeo en la segunda mitad del siglo Xx, parece sin embargo dar muestras de agotamiento y crisis ante los nuevos contextos constitucionales. Sobre el tema vid., por todos, Prieto sanchis, «Sobre el neoconstiucionalismo y sus implicaciones» en Justicia Constitucional y Derechos Fundamentales, Madrid, 2003, y las compilaciones a cargo de Carbonell,
} 


\subsubsection{LOS LÍMITES DE LA EFICACIA ORDENADORA DE LA CONSTITUCIÓN}

La segunda matización aludiría no tanto a las características internas de este orden jurídico, como a la capacidad real de ordenación normativa de la Constitución. Parece claro que, de un modo más o menos acentuado, el constitucionalismo guarda relación con lo que puede denominarse el proyecto racionalista de la modernidad. En la base de la idea constitucional se encuentra una pretensión constructivista del mundo político a través del Derecho.

Por otra parte, el moderno sistema de Derecho constitucional ha funcionado tras la II Guerra Mundial con un esquema, que, en los conocidos términos de Wahl ${ }^{63}$, constituiría un «triángulo mágico»: imperativo constitucional de realización del sistema de valores incorporado al orden constitucional, judicialización del control de esta realización a través de las jurisdicciones constitucionales, y libertad de configuración del legislador en su cualidad de concretizador de estos valores normativos constitucionales.

En la actualidad, sin embargo, cualquier observador atento puede evidenciar disfunciones en este esquema de explicación. El equilibrio resulta cada vez más inestable entre unos sistemas sociales en permanente transformación como algo inherente a su naturaleza, y una Constitución ampliamente normativa que pretende convertirse en elemento de estabilidad del conjunto ${ }^{64}$. La creciente búsqueda de respuestas adecuadas a la complejidad y autoorganización in crescendo del sistema social implica en el fondo la aceptación de la existencia de un «déficit regulativo» de la norma fundamental, algo que caracteriza al Estado democrático contemporáneo, y que lleva a hablar de pérdida de centralidad político-jurídica de la Constitución.

El debilitamiento de esta función de ordenación normativa del texto constitucional está sin duda en el origen del relieve que últimamente han alcanzado en el ámbito de nuestra disciplina las teorías sociojurídicas que explican el sistema social en términos de una pluralidad de sistemas autogenerados o autopoiéticos. Es conocido el protagonismo de Luhmann en estas últimas propuestas y también sus dificultades de comprensión para el no especialista. Se remarcarán aquí tan solo algunos de los aspectos más gene-

Neoconstitucionalismo(s), Madrid, 2003 y Teoría del Neoconstitucionalismo, Madrid, 2007. Posturas mucho más matizadas pueden encontrarse en la obra de Aguilo, Atienza y Ruiz Manero, Fragmentos para una Teoría de la Constitución, Madrid, 2007, o Moreso, La Constitución: modelo para armar, Madrid, 2009. Una cierta reacción contra estos planteamientos y contra el «exceso» de constitucionalización del ordenamiento, en la importante obra de Laporta, El imperio de la Ley. Una visión actual, Madrid, 2007. En todo caso, todas estas obras demuestran el muy importante papel que la reflexión sobre aspectos de la Teoría de la Constitución juega en la iusfilosofía contemporánea.

${ }^{63}$ Wahl, «Der Vorrang der Verfassung» en Der Staat 1, 1981.

${ }^{64}$ Porras Nadales, «Derecho Constitucional y evolucionismo jurídico», en Revista de Estudios Políticos, 1995, pp. 107 y ss. 
rales de este tipo de construcción y ello en cuanto se encuentran en la base de algunos de los nuevos enfoques del Derecho constitucional.

La construcción de Luhmann y su escuela pretende ser, ante todo, como es sabido, una teoría general de la sociedad, no pues exclusiva ni prioritariamente sociojurídica, que parte de la imposibilidad de encontrar un centro único de observación y descripción del fenómeno social ${ }^{65}$. Su clave se encuentra en la elaboración de una teoría de la evolución social que la base en la progresiva diferenciación funcional entre los distintos sistemas sociales. Los diferentes ámbitos sociales se irían organizando a través de su especialización en distintas funciones. La diferenciación funcional permitirá a cada sistema una reducción de la complejidad del ambiente que, en conjunto, implicará sin embargo una mayor complejidad del sistema social. Entre los sistemas particulares no existen relaciones de jerarquía ni de causalidad. $\mathrm{Su}$ naturaleza es esencialmente autorreferencial, un sistema solamente puede determinar sus límites y su identidad si introduce una diferencia dentro/fuera, si se diferencia en suma del «ambiente». La idea de autopoiesis alude pues a esa capacidad de los sistemas para construir por sí mismos sus propias identidades y diferencias, para procesar sus informaciones, en códigos binarios, y las conexiones que establecen con su entorno.

Desde esta perspectiva autopoiética, Luhmann no ha prescindido del estudio de los sistemas políticos y jurídicos. Su concepto de la Constitución como fruto de un «acoplamiento estructural» entre estos dos últimos sistemas, que permite la diferenciación entre autorreferencialidad y heterorreferencialidad en las operaciones internas al ámbito político o jurídico, pretende salvar la inevitable naturaleza dual del fenómeno constitucional ${ }^{66}$. Por otra parte, su análisis del problema del Estado del bienestar como el de un exceso de sobrecarga del entorno sobre el sistema jurídico, que le impide autoprocesar los límites de su identidad, aportó una lectura de altura teórica a las corrientes más críticas con la expansión de los derechos prestacionales ${ }^{67}$. Desde el ámbito estrictamente constitucional, la crítica de Habermas parece sin embargo oportuna: la radical separación metodológica entre política y Derecho, ni responde a la realidad, ni permite explicar de ningún modo la legitimación democrática del Estado constitucional ${ }^{68}$. Por otra parte, el presupuesto teórico según el cual ningún sistema puede ser analizado simultáneamente desde dentro y desde fuera, convierte al Derecho en una realidad

${ }^{65}$ Sobre la concepción sistemática de Luhmann, vid. Camou y Esteban, La sociedad compleja. Ensayos en torno a la obra de Nicolas Luhmann, México, 1997 o «La otra postmodernidad: la teoría de los sistemas» en Historia de la Teoría Política, vol. 6, Madrid 2006.

${ }^{66}$ Luhmann, La Costituzione come acquisizione evolutiva, op. cit., pp. 110.

${ }^{67}$ Idem, La teoría política en el Estado del Bienestar, Madrid, 1993.

${ }^{68}$ Habermas, Facticidad y Validez, op. cit., pp. 432-33. 
«aproblemática», cuando justamente su expansión conduce a un permanente debate público donde los elementos valorativos juegan un papel determinante $\mathrm{e}^{69}$.

Más allá de la concreta postura de este autor, y de las posibles implicaciones ideológicas de estos planteamientos, las teorías de este sociologismo jurídico han planteado sin duda importantes interrogantes sobre las funciones y los problemas actuales del ordenamiento constitucional. En un nivel general, y de manera sintética, han subrayado algunos aspectos a veces olvidados por la teoría juríco-constitucional. En primer lugar, han puesto el acento sobre el evidente nivel de complejidad alcanzado por las sociedades actuales y la relativa autonomía de los diversos ámbitos o sistemas que las componen. En segundo término, han detectado correctamente las dificultades del sistema jurídico para proceder a la «juridificación» de muchas de las demandas que le llegan desde los distintos sistemas sociales. En este aspecto, como señalan algunos autores ${ }^{70}$, han constituido un aviso y un antídoto ante los peligros de una excesiva mediatización del derecho por la política. En último lugar, y a la inversa, iluminan las múltiples resistencias que los diversos sectores de la realidad ofrecen ante su juridificación. Desde el momento en que la relación entre sistemas no es de causa/efecto, sino de interrelación y perturbación, queda en cuestión la frecuentemente presumida eficacia de la regulación de ciertos ámbitos sociales. La «interferencia» del Derecho provocará procesos de reajuste no siempre normativamente controlables, y no dejará de tener consecuencias para el propio sistema jurídico en cuanto tal. El discurso autopoiético implica pues una desconfianza y un claro escepticismo hacia la racionalización jurídica, que comparte así en el fondo, ya que no en la forma, algunos de los rasgos del discurso posmoderno ${ }^{71}$.

La mayor o menor aceptación de las premisas sistemáticas no impide, sin embargo, reconocer la existencia de problemas reales en la eficacia normativa de la Constitución, que una teoría general del Derecho constitucional no puede obviar. Se ha hablado así de una «crisis de materialización del Derecho constitucional», en cuanto a su falta de adecuación al cambio en los ámbitos sociales que se regulan, y de una «crisis de reflexión del Estado social del Derecho», en cuanto a su incapacidad para generar un sistema de respuestas coherentes y unitarias al exceso de expectativas sociales ${ }^{72}$. Cano-

\footnotetext{
${ }^{69}$ Vid. también su crítica al «estatismo» implícito en la noción de sistema jurídico, o a la imposibilidad de introducir una racionalidad normativa que distinga lo justo de lo injusto dentro de un sistema legal en el que solo se encuentran respuestas basadas en el binomio jurídico/no jurídico, Facticidad y Validez, op. cit., pp. 412-414 y 563 y ss.

${ }^{70}$ Vid. Hespanha, Panorama histórico da cultura jurídica europea, op. cit., pp. 259 y ss.

${ }^{71}$ Vallespin F, « La otra postmodernidad: la teoría de los sistemas», op. cit.

${ }^{72}$ Vid. Teubner (ed.), Dilemmas of Law in the Welfare State, Berlín, 1986, o Habermas, Problemas de legitimación en el capitalismo tardio, Madrid, 1972.
} 
tilho, sensible a un problema que le obliga a renunciar a su concepción programática de la Constitución, añadirá los problemas de «referencia» de una Constitución dirigida al individuo o el Estado, ante las nuevas entidades organizativas o neocooperativas, los problemas de fundamentación y universalización del discurso constitucional frente a otro tipo de discursos, y el problema evidente, en un ámbito europeo y globalizado, de la «reinvención del territorio». Es este el marco en el que se propugna un «Derecho constitucional sin centro», un Derecho reflexivo, dúctil, líquido, posmoderno o postintervencionista, entre otras múltiples calificaciones ${ }^{73}$.

Las características de posturas doctrinales tan matizadas y plurales sólo pueden sintetizarse aproximativamente. Parten en primer lugar de la conciencia de la crisis regulativa de la Constitución y de su pérdida relativa de centralidad y carácter planificador. En segundo término, aceptan con Teubner que debe superarse la dicotomía política/derecho, reforzando la consideración del papel y autonomía de los sistemas sociales en su relación con los sistemas anteriores ${ }^{74}$. En tercer lugar, conciben el binomio normatividad/normalidad helleriano en términos de un continuo proceso de ajuste y aprendizaje entre sistemas, donde la función prescriptiva de la Constitución se atenúa en aras de la necesaria adaptación sistemática. Por último, subrayan el papel del Derecho constitucional como «discurso» no dominante pero sí posiblemente integrador de las distintas lógicas sociales ${ }^{75}$. En definitiva, y a pesar del evidente peligro de debilitar la normatividad del texto constitucional, y de la dificultad de encontrar una plasmación concreta de unos postulados tan abstractos, vienen a llamar la atención sobre la existencia de unos límites a la eficacia y función de la norma, inherentes a su naturaleza y a su entorno. O como sabiamente ya afirmó García Pelayo respecto a este tema, «es conveniente no recaer en el mito del verbo» ${ }^{76}$.

\subsection{La Constitución como orden fundamental de la Comunidad}

\subsubsection{LA CONSTITUCIÓN COMO MARCO Y COMO DECISIÓN FUNDAMENTAL}

La noción de orden jurídico fundamental remite en el propio pensamiento de Hesse a la relación existente entre la determinación de un contenido

\footnotetext{
${ }^{73}$ Canotilho, Direito Costitucional, op. cit., pp. 1392 y ss. y 1370 y ss.

${ }^{74}$ Teubner, en Dilemas, op. cit. o «Globalización y constitucionalismo social: alternativas a la teoría constitucional centrada en el Estado», en Globalización y Derecho. Anuario de la Universidad Autónoma de Madrid, n. ${ }^{\circ}$ 9, 2005, pp. 199 y ss, vid. también Porras Nadales, Derecho Constitucional y evolucionismo jurídico, op. cit., pp. 111 y ss.

${ }^{75}$ Vid. Habermas, Facticidad y validez, op. cit., pp. 424 y ss. No muy lejos de estas posturas, Zagrebelsky, El derecho dúctil, op. cit., pp. 14 y ss.

${ }^{76}$ García Pelayo, Obras completas, Madrid, 1991, Tomo III, pp. 1362.
} 
material esencial y la necesaria apertura de la norma fundamental que posibilite el juego democrático y la evolución histórica. Es precisamente este equilibrio el que ha determinado en parte la aceptación general de esta concepción. En este contexto, un elemento indicativo de la incuestionable relación entre Teoría de la Constitución y dogmática del Derecho constitucional, lo constituye la conocida polémica doctrinal que protagonizarán principalmente Böckenförde y Alexy en torno a las consecuencias del principio de proporcionalidad como método de concretización de los derechos fundamentales.

Como es sabido, Böckenförde critica con dureza la concepción de los derechos como principios y el carácter objetivo de valor de los que los dota la jurisprudencia alemana. Una incorrecta dogmática de los derechos fundamentales conduciría así a anular el carácter de ordenamiento-marco del texto fundamental, y a entender la Constitución como un orden jurídico fundamental donde «todos los principios y todas las posibilidades de compromiso para la conformación del ordenamiento jurídico están ya in nuce contenidos en ella», convirtiendo por ende al Tribunal Constitucional en el señor de la Constitución ${ }^{77}$.

Significativamente, Alexy, en su trabajo titulado «Derecho constitucional y Derecho ordinario» ${ }^{78}$, intentará rebatir la crítica encuadrándola en el contexto de la Teoría de la Constitución. Según el autor, el problema básico de la relación entre Constitución y ordenamiento se sitúa en las coordenadas de la validez formal y la densidad normativa material. Asumida en los ordenamientos actuales la máxima validez formal, esta solo es admisible bajo la condición de que la densidad normativa material esté suficientemente delimitada y determinada.

La actual concepción de los derechos fundamentales es, sin embargo, la historia de una expansión material de la Constitución. Esto ha supuesto una constitucionalización material del ordenamiento jurídico que afecta directamente a los poderes públicos y a su margen de acción. La «sobreconstitucionalización» tan solo es evitable, por tanto, con una intensificación de la dogmática de los «márgenes de acción». Con ello podría compatibilizarse, en contra de la opinión de una parte de la doctrina alemana (Böckenförde, pero también Wahl o Starck), la idea de Constitución como orden marco y como orden fundamental.

${ }^{77}$ Böckenförde, «Sobre la situación de la dogmática de los derechos fundamentales tras cuarenta años de Ley Fundamental», en Escritos sobre los derechos fundamentales, op. cit., pp. 131 y ss.

${ }^{78}$ En el n. ${ }^{\circ} 61$ de la Veröffentlichungen der Vereinigung der Deutschenstaatsreechtsleher, Berlín, 2002. Vid. también Epílogo a la Teoría de los Derechos Fundamentales, Madrid, 2004, y en la misma línea «Sobre los derechos sociles a protección» en Derechos sociales y ponderación, Madrid, 2007. 
En síntesis, se trataría de distinguir entre un margen de acción estructural, formado a partir de los límites de lo que la Constitución ordena y prohíbe, y un margen de acción epistémico, que se forma a partir de los límites de la capacidad para reconocer «por una parte lo que ordena y prohíbe la Constitución y por otra lo que no ordena ni prohíbe». Aplicando el concepto de margen de acción a la ponderación de derechos fundamentales, en los casos de empate, se mantiene que existe un margen de acción para el legislador, lo que implica una novedad frente al principio de «favor iusfundamentalis» de la Teoría de los derechos fundamentales. Desde el punto de vista de la Teoría de la Constitución, esta postura supone una acentuación del factor de libre configuración democrática dentro del ordenamiento, y una cierta consciencia por parte un representante significado de la perspectiva analítica de sus límites.

\subsubsection{LA LEGITIMIDAD DEMOCRÁTICA COMO FUNDAMENTO DE LA CONSTITU- CIÓN: PLURALISMO Y CONSTITUCIONALISMO MULTINIVEL}

La concepción de la Constitución como orden jurídico fundamental de la comunidad alude también, y más allá de la supremacía formal, al contenido material de la norma y, por tanto, en palabras de Hesse, a su carácter de «orden con un contenido determinado, recto y por ello legítimo» ${ }^{79}$. El texto fundamental cumple así la doble función de conferir legitimidad al orden político y de dotar de legitimación a los respectivos titulares del poder político. No puede olvidarse sin embargo que, como ya de forma clásica escribió Rubio Llorente, por Constitución solo cabe entender «una ordenación de la vida social en el que la titularidad de la soberanía corresponde a las generaciones vivas y en el que, por consiguiente, las relaciones entre gobernantes y gobernados están reguladas de un modo tal que estos disponen de unos ámbitos reales de libertad que les permiten el control efectivo de los titulares ocasionales del poder. No hay otra Constitución que la Constitución democrática ${ }^{80}$. El principio de legitimación del Estado constitucional es pues esencialmente el democrático, en cuanto existe una conexión ineludible entre el principio de soberanía popular y los derechos fundamentales. Algo que ha señalado desde siempre la doctrina constitucional y que se convierte en el último Habermas en el elemento clave de legitimación del propio Derecho en cuanto tal ${ }^{81}$. Una teoría general de la Constitución no puede, pues, obviar la trascendencia del elemento democrático como principio de legitimación original y permanente del Estado, ni las consecuencias que se des-

\footnotetext{
${ }^{79}$ Hesse, «Concepto y cualidad de la Constitución», op. cit., pp. 15.

${ }^{80}$ Rubio Llorente, «La Constitución como fuente del derecho», La forma del poder, Madrid, 1985, pp. 87.

${ }^{81}$ Habermas, Facticidad y validez, op. cit., pp. 168 y 169.
} 
prenden de su entendimiento como principio constitucional ${ }^{82}$. No parece consecuente, pues, que el constitucionalista no tenga en cuenta las disfunciones que en esta función de legitimación se están produciendo en los Estados contemporáneos ${ }^{83}$.

De hecho, las grandes aportaciones de un Rawls o un Habermas han podido considerarse como la búsqueda de un punto de acuerdo sobre los fundamentos de la asociación y de la obligación política ${ }^{84}$. En ambos, como señala Günther, los derechos básicos deben interpretarse como la condición que hace posible el proceso de autodeterminación democrática ${ }^{85}$. Y ambos también han ido centrando sus reflexiones desde perspectivas más filosóficas o sociológicas hacia la consideración de los grandes temas jurídico-políticos. El «giro político» de Rawls, que ya era obvio en su libro Liberalismo políti$c o^{86}$, se acentúa, o al menos se clarifica, en una de sus últimas obras ${ }^{87}$, donde expresamente se mantiene que su teoría de la justicia «es una concepción política independiente que articula valores políticos y constitucionales fundamentales» ${ }^{88}$. El «giro jurídico» habermasiano se plasma en una obra ${ }^{89}$ que constituye a la vez un gigantesco esfuerzo por revitalizar el valor normativo del Derecho como elemento de legitimidad del orden social, y todo un manual de Derecho constitucional donde se recogen, desde un punto de vista crítico, las teorías sobre el Estado social, sobre la jurisdicción constitucional, sobre la naturaleza principal del ordenamiento y, ante todo, sobre la democracia como principio constitucional fundamental. La revitalización del contractualismo como base de la comunidad política en Rawls y su integración con el pluralismo, o la concepción procedimental-deliberativa del ordenamiento en Habermas, por mencionar tan solo a estos dos autores, son elementos necesarios para la comprensión del mundo jurídico constitucional de nuestro días. Son un buen ejemplo de cómo, en palabras de Canotilho, sin ideas no se puede hacer Derecho constitucional.

El intento de repensar a un nivel teórico tan general los fundamentos de la legitimación del sistema político convive con una literatura desbordante en

\footnotetext{
${ }^{82}$ Böckenförde, «La democracia como principio constitucional», op. cit., pp. 76 y ss.

${ }^{83}$ Por todos, Dahrendorf, Después de la democracia, Barcelona, 2002, Pasquino, La democracia exigente, Madrid, 2000, Beck, La Democracia y sus enemigos, Barcelona, 2000.

${ }^{84}$ Vid. «Introducción» a Habermas/Rawls, Debate sobre el liberalismo político, Barcelona, 1998, pp. 11.

${ }^{85}$ «¿Impera el derecho sobre la política?» en Política y derecho, ¿se oponen la democracia y el constitucionalismo? La Política, 1998, pp. 7.

${ }^{86}$ Rawls, El liberalismo político, Barcelona, 1996, pp. 35 y ss.

${ }^{87}$ Ídem. La justicia como equidad. Una reformulación, Barcelona, 2002, pp. 70 y ss.

${ }^{88}$ Ibídem.

${ }^{89}$ Habermas, Facticidad y validez, op. cit.
} 
torno a la realidad del sistema democrático, en una línea general de denuncia ante la existencia, también en el interior de los sistemas nacionales, de un «déficit democrático». Como señala Manuel Castells, tras los cambios sociales y tecnológicos, las ideologías políticas que emanan de las instituciones y organizaciones industriales y del liberalismo democrático basado en el Estado nación corren el riesgo de verse privados de significado real en el nuevo contexto social ${ }^{90}$. El «discurso» jurídico-constitucional puede integrar, sin embargo, al nivel de la Teoría General de la Constitución, las sugerencias que las teorías normativas de la democracia -liberal, comunista o republicana- aportan para una correcta comprensión, tanto de los derechos fundamentales de participación, como de la necesidad de una concepción de la libertad que, como señala Skinner, vaya más allá de la «libertad negativa de los modernos ${ }^{91}$. Solo una fundada perspectiva teórica puede servir de instrumento crítico para enjuiciar las concretas intervenciones en estos campos desde el Derecho positivo.

Por otra parte, desde la perspectiva europea, la concepción normativa de la democracia que se mantenga no es indiferente a la hora de abordar el problema del pluralismo y de la que ya puede llamarse «construcción constitucional europea». Ambos son aspectos necesarios de una Teoría de la Constitución «temporalmente adecuada» y enlazan el problema de la fundamentalidad de la Constitución con esa problemática «Comunidad» a la que regula y en la que sustenta el orden jurídico constitucional. ${ }^{92}$

El pluralismo, cuyo concepto era entendido en el constitucionalismo europeo fundamentalmente desde una dimensión política o social, se ha convertido en la realidad de Europa occidental en un pluralismo basado en el origen. El problema de lo que Habermas consagró como «la inclusión del otro ${ }^{93}$ no es abordado por igual desde una perspectiva comunitarista que prime los valores culturales identitarios $\left(\right.$ Taylor $^{94}$ ), o la idea de identidad

${ }^{90}$ Castells, La era de la información. Economía, sociedad y cultura. El poder de la identidad, v. II, Madrid, 1998, pp. 3944, vid. también recientemente, Comunicación y poder, Madrid, 2009, pp. 261-392.

${ }^{91}$ Skinner, La libertá prima del liberalismo, Turín, 1998, pp. 78 y ss. Una distinción clásica entre las tres principales teorías normativas de la democracia en Habermas, «Tres modelos normativos de la democracia» en La inclusión del otro, Barcelona, 1999, pp. 231 y ss. Vid. también desde un punto de vista más histórico, Held, Modelos de Democracia, op. cit. Una comparación entre la cosmovisión «liberal» y la «democrática» del Estado, en Del Aguila, «El centauro transmoderno: liberalismo y democracia en la democracia liberal», en Historia de la Teoría Política. op. cit., v. 6, pp. 549. Sobre los modelos de democracia como modelos culturales, vid. Giner, «Cultura republicana y política del porvenir», en $\mathrm{La}$ cultura de la democracia: el futuro, Barcelona, 2000, pp. 135.

${ }^{92}$ Habermas, «Inclusión: ¿incorporación o integración? Sobre la relación entre nación, Estado de derecho y democracia» en La inclusión del otro, op. cit., pp. 123 y ss.

${ }^{93}$ Habermas, La inclusión del otro, op. cit., pp. 107 y ss.

94 Taylor, Multiculturalismo y política del reconocimiento, México, 1993. 
nacional (Böckenförde) ${ }^{95}$, que por quien desde un paradigma procedimentalista de la democracia considere que la formación política de la opinión y la voluntad no tienen lugar únicamente en forma de compromisos, sino también según un modelo de discusión pública que fundamente su legitimi$\operatorname{dad}^{96}$.

Por último, es esta diversa concepción de la comunidad que sustenta la soberanía popular la que se encuentra en el centro del debate entre quienes consideran que una constitución europea no puede tener suficiente legitimación por no existir una homogénea comunidad popular ${ }^{97}$ y quienes creen que esta identidad colectiva no necesita ser previa, sino que es constituible a través del propio proceso democrático ${ }^{98}$. Parece claro, no obstante, que, como señala Canotilho, dentro de la Teoría de la Constitución, es necesario actualmente incluir una teoría de la «interconstitucionalidad», entendida como el estudio de las relaciones de concurrencia, yuxtaposición y conflicto entre distintas Constituciones y distintos poderes constituyentes en un mismo espacio político ${ }^{99}$, lo que, en terminología de origen anglosajón, ha terminado denominándose constitucionalismo multinivel ${ }^{100}$, y ha llevado, en el ámbito de la Unión Europea, a hablar de «concertación constitucional», «pluralismo constitucional», «inclusión constitucional», «constitucionalismo dual», o «Comunidad constitucional (Verfassungsverbund)». En el caso europeo, y desde una perspectiva coincidente con HÄBERLE ${ }^{101}$, hace tiempo que subrayó LA PERGOLA ${ }^{102}$ que la apelación al poder constituyente y a la

${ }^{95}$ Böckenförde, «Welchen weg geht Europa?», en Staat, Nation, Europa, 1999, pp. 77 y ss.

${ }^{96}$ Habermas, «Inclusión: ¿Incorporación o integración? Sobre la relación entre nación, Estado de derecho y democracia», en La inclusión del otro, op. cit,, pp. 117. Vid. también Denninger y Grimm, Derecho constitucional para la sociedad multicultural, Madrid, 2007.

${ }^{97}$ Grimm, «Una Costituzione per l'Europa?, en Il futuro della costituzione, op. cit., pp. 363

${ }^{98}$ Habermas, «¿Necesita Europa una constitución?», en La inclusión del otro, op. cit., pp. 143 y ss. y «¿Por qué Europa necesita una constitución?», en New Left Review, n. ${ }^{\circ} 11$, 2001, donde habla de «una constitución catalítica», pp. 16.

${ }^{99}$ Canotilho, Direito Constitucional e Teoria da Constituição, op. cit., pp. 1407-1412.

${ }_{100} \mathrm{Vid}$. en español, Bustos Gisbert, La constitución red: un estudio sobre supraestatalidad y constitución, Oñate, 2005. En la literatura sobre la Unión Europea, por todos, Pernice, «Multilevel constitucionalism in the European Union», en European Law Review, vol. 27/5, 2002. Con una visión más general, Bilacia y Pizzetti, Aspetti e problema del costituzionalismo multilivello, Milán, 2004.

${ }^{101}$ Haberle, El Estado Constitucional, op. cit., pp. 66.

${ }^{102}$ La Pergola, «¿Para qué una Constitución de la Unión Europea?», en Los nuevos senderos del federalismo, op. cit., pp. 181 y ss. Por todos, las aportaciones de Haberle, Habermas, Ferrajoli o Vitale en La Constitucionalización de Europa, México, 2004. 
Constitución deben confiarse al desarrollo de un europeísmo maduro y constructivo, consciente de sus posibilidades de éxito. En todo caso, el debate en torno a la frustrada Constitución europea mostró claramente cómo en el proceso de integración europea resultaba ya ineludible una clarificación teórica que discurriera en términos y con categorías constitucionales, y cómo también, en palabras de Cruz Villalón, «el debate europeo devuelve como un espejo la imagen de la Constitución sobre el propio campo de la Teoría de la Constitución, en la medida en que viene a cuestionar la actual razón de ser de algunos de los postulados clásicos en los que la Constitución aspira a reconocerse» ${ }^{103}$.

${ }^{103}$ Cruz Villalón, La Constitución inédita. Estudios ante la constitucionalización de Europa, Madrid, 2004, pp. 23. La obra es a nuestro juicio el más brillante estudio en castellano sobre los elementos de Teoría de la Constitución implicados en el proceso de integración. Vid. también en esta línea, por todos, los trabajos compilados por Zagrebelsky, en Diritti e Constituzione nell'Unione Europea, Milán, 2005. 